\title{
REVITALISASI NILAI-NILAI KEARIFAN LOKAL BAGI UPAYA RESOLUSI KONFLIK
}

\author{
Suprapto \\ IAIN Mataram \\ e-mail: suprapto@yahoo.co.id
}

\begin{abstract}
The involvement of local wisdom in conflict resolution and peace building is not the only way to resolve conflict. Some level of conflict resolution should be there along the path of conflict resolution. The stressing on the patterns of conflict resolution is still limited on conflict settlement and need to develop toward peace building involving local wisdom which ic proven to be able to maintain social harmony. Considering to the norms had been long internalized among society, the society members strongly held the society order. The most important in this context is the need in the side of the elites to discuss the patters of local wisdom based peace building.
\end{abstract}

\begin{abstract}
$* * *$
Keterlibatan kearifan lokal dalam upaya resolusi konflik dan pembangunan perdamaian bukan satu-satunya jalam untuk menangani konflik. Harus ada beberapa tingkatan resolusi konflik. Penekanan pada pola resolusi konflik masih terbatas pada penghentian konflik dan perlu dikembangkan ke arah pembangunan perdamaian yang melibatkan kearifan lokal yang terbukti mampu mempertahankan harmoni sosial. Dengan mempertimbangkan pada norma-norma yang telah lama terinternalisir di kalangan masyarakat, maka anggota masyarakat akan mempertahankan norma yang dimilikinya secara kuat. Hal yang paling penting dalam konteks ini adalah perlunya para elite untuk membicarakan tentang pola kearifan lokal yang didasarkan pada pembangunan perdamaian.
\end{abstract}

Keywords: peace building, kearifan lokal, resolusi konflik 


\section{A. Pendahuluan}

Dalam dua dekade terakhir realitas harmoni Indonesia kerap terkoyak oleh serangkaian konflik berbau kekerasan (violence conflicts) yang marak merebak di berbagai daerah ${ }^{1}$ termasuk di Lombok Provinsi Nusa Tenggara Barat.2 Selain meyebabkan jatuhnya korban jiwa yang tak sedikit, ${ }^{3}$ konflik juga mengakibatkan dampak sosial yang luar biasa. Berbagai konflik komunal ini bukan hanya sangat mengganggu stabilitas nasional tetapi juga mengancam integrasi bangsa. Komunitas kebangsaan yang diangankan sebagai sebuah bangunan yang solid, sontak berubah menjadi sebuah komunitas semu yang menurut Benedict Anderson tak lebih hanya sebatas komunitas imajiner. ${ }^{4}$ Inilah sebetulnya tantangan terberat bangsa Indonesia sebagai bangsa yang tersusun secara multikultur, multietnik, dan multiagama yang rapuh dan rentan jatuh dalam perpecahan, jika bangsa ini gagal mengelolanya secara baik.

Menyikapi serangkaian konflik yang muncul diperlukan perhatian dari semua pihak. Berbagai upaya penanganan konflik yang selama ini dilakukan elit masyarakat maupun pemerintah terkesan hanya menyelesaikan atau

\footnotetext{
${ }^{1}$ Dari data yang terekspose melalui media massa, kerusuhan-kerusuhan itu antara lain terjadi di Purwakarta (awal November 1995); Pekalongan (akhir November 1995); Tasikmalaya (September 1996); Situbondo (Oktober 1996); Rengasdengklok (Januari 1997); Temanggung dan Jepara (April 1997); Pontianak (April 1997); Banjarmasin (Mei 1997); Ende di Flores dan Subang (Agustus 1997) dan Mataram (Januari 2000). Selengkapnya lihat Jajat Burhanuddin dan Arif Subhan, eds., Sistem Siaga Dini terhadap Kerusuhan Sosial, Jakarta: Balitbang Agama Depag RI dan PPIM, 2000), 3. Setelah tahun 2000, kerusuhan terus terjadi seperti di Ambon, Maluku, Kalimantan dan kota lainnya di Indonesia. Selengkapnya lihat CA. Coppel, (eds.), Violent Conflicts in Indonesia: Analysis, Representation, Resolution, London: Routledge, 2005; dan Gerry van Klinken, Communal Violence and Democratization in Indonesia: Small Town Wars, (London: Routledge, 2007).

2 Selain kerusuhan Januari tahun 2000 yang terkenal dengan "kasus 171," berbagai kerusuhan berbau kekerasan di Lombok, sering menghiasi media massa. Perang antar kampung seperti di Ketare Lombok Tengah dan Karang Genteng Kota Mataram adalah beberapa contoh kerusuhan massa yang hingga kini masih sering terjadi. Lihat, Khamami Zada dkk., Prakarsa Perdamaian: Pengalaman dari Berbagai Konflik Sosial, (Jakarta: Lakpesdam NU, 2008), h. 89-95.

3 Estimasi jumlah korban dari setiap konflik, lihat Jacques Bertrand, Nationalism and Ethnic Conflict in Indonesia, New York: Cambridge University Press, 2004, h. 1. Tingginya Komunal konflik juga dapat dilihat dalam Ashutosh Varshney et.al., "Pattern of Collective Violence in Indonesia (19902003)," UNSFIR (United Nation Support Facility for Indonesian Recovery), (Jakarta: Report UNSFIR, 2004), pp. 25-27.

4 Lihat Benedict Anderson, Imagined Communities: Reflections on the Origin and Spread of Nationalism, London and New York: Verso, 1991, pp. 5-7. Konsepsi lebih lanjut mengenai nationality dan nationalism dapat dibaca pada Craig Calhoun, "Nationalism and Civil Society: Democracy, Diversity and Self Determination" in Social Theory and The Politics of Identity, ed. Craig Calhoun, (Oxford: Blackwell Publisher, 1998), pp. 312-321.
} 
mengakhiri konflik, belum mengarah pada upaya transformasi konflik (conflict transformation) secara berkesinambungan (istimrar). Akibatnya, meskipun konflik terlihat berhenti tetapi potensi konflik yang sama bisa saja muncul di lain waktu. Konflik dalam masyarakat merupakan sesuatu yang given. Keberadaanya acap mengiringi dinamika sebuah masyarakat. Eksistensi konflik dengan demikian merupakan sesuatu yang alamiah dan wajar. ${ }^{5}$ Akan tetapi ketika konflik telah mengarah pada tindak kekerasan dan anarkhi maka dampak positif konflik sebagai sarana kohesivitas dan soliditas sebuah grup, kemudian berubah menjadi sesuatu yang desktruktif. Untuk itu diperlukan upaya alternatif yang berbeda dari cara-cara penyelesaian konflik yang selama ini ada.

Pola penanganaan yang melibatkan partisipasi masyarakat secara luas dengan memanfaatkan kearifan-kearifan lokal ${ }^{6}$ masyarakat merupakan alternatif resolusi konflik yang patut dipertimbangkan. Melalui kesediaan berbagai aktor lokal yang terlibat dalam konflik dan memanfaatkan kebijaksanaan setempat diharapkan konflik akan dapat diarahkan menjadi energi positif bagi masyarakat.

Tulisan ini berisi tentang kajian mengenai serangkaian konflik yang terjadi di Lombok, berikut pola-pola penanganan yang dilakukan. Beberapa kearifan lokal masyarakat Lombok yang terekam dalam Sesengak (peribahasa), Perteke, atau Lelakaq (pantun) juga akan dikaji sebagai bahan pengembangan resolusi konflik di pulau yang terkenal dengan sebutan "pulau seribu masjid" ini. Selain itu berbagai tradisi yang masih efektif dipraktikan di masyarakat Lombok seperti begibung, sejumlah produk peraturan lokal

${ }^{5}$ Lewis Coser melihat bahwa konflik merupakan bagian dari dinamika masyarakat karenanya memberi efek positif bagi soliditas grup. Terdapat tiga argumentasi yang mendasari pendapatnya. Pertama, situasi konflik akan meningkatkan kohesi internal dari kelompok-kelompok terkait; kedua, mampu menciptakan assosiasi-assosiasi dan koalisi-koalisi baru dan ketiga, dengan konflik akan terbangun kesimbangan kekuatan antar kelompok terlibat Lihat, Lewis Coser, The Function of Social Conflict, (New York: Free Press, 1965).

6 Kearifan lokal atau yang kerap disebut sebagai local wisdom dimaknai sebagai usaha manusia dengan menggunakan akal budinya untuk bertindak dan bersikap terhadap sesuatu, objek atau peristiwayang terjadi dalam ruang tertentu. Lihat Nurma Ali Ridwan, " Landasan Keilmuan Kearifan Lokal" Ibda', Vol. 5, No. 1, Jan-Jun, 2007, h. 27-38.

7 Sebutan ini selain mengindikasikan banyaknya tempat ibadah yang ada di pulau ini juga secara sengaja merujuk adanya kenyataan bahwa Islam merupakan agama mayoritas di wilayah ini. Lihat John Ryan Bartholomew, Alif Lam Mim Kearaifan Masyarakat Sasak, terj. Imron Rasyidi, (Yogyakarta: Tiara Wacana, 2001), h. 86. 
dalam bentuk awig-awig juga akan dielaborasi untuk kemudian ditimbang potensinya bagi upaya resolusi konflik sekaligus upaya bina damai (peace building).

\section{B. Konflik: Konsepsi dan Resolusi}

Konflik merupakan kenyataan hidup yang tidak terhindarkan dan sering bersifat kreatif. Konflik terjadi ketika tujuan masyarakat tidak sejalan atau karena ketidakseimbangan atau kesenjangan status sosial, kurang meratanya kemakmuran dan akses yang tidak seimbang terhadap sumberdaya serta sudut pandang terhadap suatu permasalahan. Rafl Dahrendorf menyatakan bahwa konflik merupakan fenomena yang selalu hadir (inherent omnipresence) dalam suatu komunitas. ${ }^{8}$ Pada tingkatan ini, konflik sebetulnya merupakan fenomena alamiah yang menyertai pola interaksi manusia sepanjang masa. Persoalannya adalah ketika konflik berubah menjadi kekerasan atau anarkhi apalagi dengan melibatkan massa dalam jumlah yang sangat banyak. Harmoni sosial yang telah terbangun biasanya akan berubah menjadi chaos.

Ada banyak teori yang menjelaskan tentang sebab-sebab terjadinya konflik. Salah satu di antaranya adalah yang dikemukakan oleh Simon Fisher dkk yang menyebutkan beberapa teori tentang terjadinya konflik: Pertama, Teori hubungan masyarakat. Teori ini menyatakan bahwa konflik terjadi disebabkan oleh polariasi yang terus terjadi, ketidak percayaan dan permusuhan di antara kelompok yang berbeda dalam masyarakat. Kedua, teori negosiasi konflik. Menganggap bahwa konflik terjadi oleh posisi-posisi yang tidak selaras dan perbedaan pandangan tentang konflik oleh pihak-pihak yang mengalami konflik. Ketiga, teori kebutuhan manusia. Teori ini menganggap bahwa konflik disebakan oleh kebutuhan dasar manusia-fisik, mental dan sosial-yang tidak terpenuhi atau terhalangi. Keamanan, identitas, pengakuan, partisipasi dan otonomi sering merupakan inti pembicaran. Keempat, teori identitas. Teori ini berasumsi bahwa konflik disebabkan oleh karena identitas yang terancam, yang sering berakar pada hilangnya sesuatu atau penderitaan di masa lalu yang tidak diselesaikan. Kelima, teori kesalahpahaman antar budaya. Teori berasumsi bahwa konflik disebabkan oleh ketidakcocokan

8 Ralf Dahrendorf, Class and Class Conflict in Industrial Society, (Stanford: Stanford University Press, 1959,) pp. $241-248$. 
dalam cara-cara komunikasi di antara berbagai budaya yang berbeda. Dan keenam, teori transformasi konflik. Bahwa konflik disebabkan oleh ketidaksetaraan dan ketidakadilan yang muncul sebagai masalah-masalah sosial, budaya dan ekonomi.

Konflik kekerasan juga bisa dilihat dari perspektif konflik elit. Seperti diketahui pasca reformasi, selain beberapa kerusuhan, kondisi sosial politik di Indonesia ditandai dua gejala yang mencolok yakni konflik politik (political conflict) dan kekerasan politik (political violence). Tarik menarik kepentingan politik elit di satu sisi dapat menyumbang proses demokratisasi, tetapi dampak buruknya dapat memunculkan pengkotak-kotakan masyarakat yang akibatnya cenderung menimbulkan kekerasan kolektif. ${ }^{10}$

Sementara itu untuk menyelesaikan suatu konflik, ada beragam versi atau model resolusi konflik, salah satunya seperti ditawarkan oleh Johan Galtung. ${ }^{11}$ Galtung menawarkan tiga model yang saling terkait, yaitu; peace keeping, peace building, peace making. Peace keeping dilakukan ketika konflik benar-benar tak bisa dihentikan secara halus. Pelibatan aparat keamanan atau militer terpaksa ditempuh guna menghentikan konflik. Peace building merupakan strategi yang mencoba mengembalikan keadaan destruktif akibat konflik dengan jalan membangun jembatan komunikasi antara pihak yang terlibat. Sedangkan peace making, adalah upaya negoisasi antara kelompok yang memiliki perbedaan pandangan dan kepentingan.

Teori lain menyebutkan bahwa untuk menangani konflik diperlukan upaya yang disebut resolusi konflik. Resolusi konflik merupakan suatu terminologi ilmiah yang menekankan kebutuhan untuk melihat perdamaian sebagai sebuah proses terbuka dan membagi proses penyelesaian konflik melalui beberapa tahap sesuai status konflik..$^{12}$ Ada empat tahapan dalam resolusi konflik yaitu:

\footnotetext{
${ }^{9}$ Simon Fisher, et.al, Mengelola Konflik Ketrampilan dan Strategi Untuk Bertindak, terj. S.N. Karikasari dkk., (Jakarta: The British Council Responding to Conflict, t.th.), h. 4.

10 Lihat Muhsin Jamil, (ed.), Mengelola Konflik Membangun Damai: Teori, Strategi dan Implementasi Resolusi Konflik, (Semarang: Walisongo Mediation Centre, 2007).

11 Ibid., h. 78.

12 Syafuan Rozi, dkk, Kekerasan Komunal: Anantomi dan Resolusi Konflik di Indonesia, (Jakarta: Pustaka Pelajar, 2006), h. 21- 22.
} 
1. Tahap de-eskalasi konflik yang menekankan pada proses penghentian kekerasan. Militer atau aparat keamanan biasanya akan melakukan pekerjaan ini.

2. Tahap negoisasi, langkah penyelesaian yang lebih berorientasi politik dengan melibatkan kelompok-kelompok yang bertikai. Tujuannya adalah untuk memaksa para pihak untuk memasuki meja perundingan.

3. Tahap problem solving approach yang lebih bernuansa sosial. Rothman menjabarkan ada empat komponen utama pada tahap problem solving approach $^{13}$. Pertama, masing-masing pihak mengakui legitimasi pihak lain untuk melakukan inisiatif komunikasi tingkat awal. Kedua, masingmasing pihak memberi informasi yang benar tentang konflik yang sedang terjadi meliputi penyebab, trauma yang timbul, hambatan struktural yang mungkin dihadapi dalam resolusi konflik. Ketiga, kedua belah mulai mencari alternatif solusi setidaknya signal-signal menuju perdamaian. Keempat, problem solving workshop yakni kesediaan pihakpihak untuk menyediakan suasana kondusif bagi resolusi konflik.

4. Tahap peace building, yakni tahap yang bersifat kultural dan struktural. Memerlukan waktu yang panjang dan konsistensi untuk mewujudkan perdamaian yang permanen.

Dari semua konsepsi di atas, satu hal yang sangat diharapkan dalam menangani konflik adalah kesediaan pihak-pihak yang memiliki otoritas agar bertindak secara objektif dan netral. Prinsip ini perlu diambil agar pihakpihak yang terlibat tidak ada yang merasa dirugikan dan merasa puas (satisfaction). Selain langkah-langkah yang bersifat kuratif, tentu saja perlu dilakukan tindakan-tindakan yang bersifat prefentif agar potensi konflik kekerasan dapat diantisipasi.

\section{Resolusi Konflik Berbasis Kearifan Lokal}

Mengurai konflik yang terjadi di masyarakat, biasanya orang cenderung mencari model penyelesaian yang datang dari luar. Dalam banyak kasus, model penyelesaian impor semacam ini cenderung seragam. Diawali dengan penghentian konflik melalui cara-cara memaksa oleh pihak keamanan (peace

13 J. Rothman, From Confrontation to Cooperation: Resolving Ethnic and Regional Conflict, (Newbury Park, CA: Sage, 1992), p. 30. 
keeping) kemudian dilanjutkan dengan penetapan serangkain aturan termasuk sanksi bagi kedua belah pihak agar tidak mengulangi konflik. Pola semacam ini biasanya hanya efektif untuk menghentikan konflik kekerasan dalam waktu singkat tetapi kurang bisa menjamin bahwa konflik tidak akan muncul lagi di kemudian hari. Proses penyelesaian berlangsung secara ad hoc dan parsial serta kurang menyentuh akar persoalan konflik yang sebenarnya.

Kelemahan model penyelesaian seperti di atas, selain hanya bersifat sementara yang kurang dapat menjamin penghentian konflik secara permanen, juga kerap mengabaikan rasa keadilan bagi para pihak yang bersengketa. Dengan model yang memaksa, jelas tidak bisa menghilangkan rasa dendam di antara pihak-pihak yang terlibat (disputants). Para elit yang bertugas menjadi penyelesai konflik-yang karena berkeinginan untuk segera mengakhiri konflik-cenderung memihak kepada mereka yang kuat. Alih-alih menjadi mediator yang mesti bertindak netral dan adil, elit kerap terjebak mengikuti kemauan kelompok mayoritas..$^{14}$ Akibatnya, acap terjadi apa yang disebut victimizing victim (mengorbankan korban). Korban yang hendak mencari keadilan malah digiring menjadi kelompok yang harus mengalah dan dipaksa mengikuti kehendak kelompok mainstream.

Sesuai dengan jenis, bentuk dan dinamika konflik, pola manajemen konflik sebetulnya juga sangat beragam. Kemampuan para elit untuk memilih cara-cara yang tepat dengan melibatkan berbagai pendekatan politik, ekonomi dan sosial secara komprehensif akan membantu mengurai konflik secara tuntas.

Salah satu domain penting tetapi luput dari perhatian para elit dalam penanganan konflik adalah melalui pendekatan "dari dalam" masyarakat sendiri. Masyarakat sebetulnya memiliki kemampuan dan sensivitas yang disebut "kearifan lokal" dalam menjaga kelangsungan dinamika masyarakat termasuk mengantispasi bahaya yang mengancam dan menyelesaikan konflik. Memberdayakan kearifan lokal sebagai alternatif solusi dalam penanganan konflik merupakan pendekatan budaya dalam menyelesaikan konflik. ${ }^{15}$

\footnotetext{
${ }^{14}$ Jika dirunut, ketidak-netralan elit bahkan menjadi tren bagi elit negara. Berlarut-larutnya penyelesaian kekerasan yang menimpa warga Ahmadiyah misalnya, diakibatkan oleh negara yang sering absen dan bahkan menyokong kekerasan dan tindak intoleransi dari sebagian warga. Lihat Nicola Colbran, "Realities and Challenges in realising freedom of Religion or belief in Indonesia," The International Journal of Human Rights, Vol. 14, No. 5, September, 2010, pp. 678- 704.

15 Irwan Abdullah, dkk (ed.)., Agama dan Kearifan Lokal dalam Tantangan Global, (Yogyakarta: Pustaka Pelajar, 2008), h. 7.
} 
Kearifan lokal, menurut John Haba sebagaimana dikutip oleh Irwan Abdullah, ${ }_{1}^{16}$ "mengacu pada berbagai kekayaan budaya yang tumbuh dan berkembang dalam sebuah masyarakat yang dikenal, dipercayai dan diakui sebagai elemen-elemen penting yang mampu mempertebal kohesi sosial di antara warga masyrakat". Setidaknya ada enam signifikansi dan fungsi kearifan lokal jika dimanfaatkan dalam resolusi konflik. Pertama, sebagai penanda identitas sebuah komunitas. Kedua, elemen perekat (aspek kohesif) lintas warga, lintas agama dan lintas kepercayaan. Ketiga kearifan lokal tidak bersifat memaksa tetapi lebih merupakan kesadaran dari dalam. Keempat, kearifan lokal memberi warna kebersamaan sebuah komunitas. Kelima, kemampuan local wisdom dalam mengubah pola fikir dan hubungan timbal balik individu dan kelompok dan meletakkannya di atas common ground. Keenam, kearifan lokal dapat mendorong proses apresiasi, partisipasi sekaligus meminimalisir anasir yang merusak solidaritas dan integrasi komunitas.

Rekomendasi perlunya melibatkan "orang dalam" melalui kearifan lokal sebagai alternatif resolusi konflik sebetulnya bisa digunakan untuk kasuskasus konflik bernuansa agama. Meskipun agama masih diperdebatkan sebagai unsur budaya atau bukan dalam konstruksi sosial masyarakat, tetapi fakta historis memperlihatkan bahwa proses integrasi dan harmoni di antara keyakinan yang berbeda yang pernah hidup di Indonesia dapat berlangsung justeru karena kontribusi kearifan lokal dalam merawat dan mengelola perbedaan tersebut. ${ }^{17}$

Hanya saja, berbagai kearifan lokal yang mungkin dikembangkan di negeri ini masih saja membutuhkan apresiasi dan penguatan dari para elit agar kearifan lokal ini bekerja (workable) secara baik. Para pemimpin tradisional adalah penggerak yang menentukan harmoni sosial pada suatu komunitas. Sebuah penelitian yang dirilis di tahun 2008, menunjukkan

16 Ibid., h. 27.

17 Berbagai penelitian menunjukan akan efektivitas kearifan lokal dalam merawat pluralitas beragama. Penelitian yang dilakukan Kadri dkk, tentang harmoni sosial antara pemeluk agama Kristen dan Islam yang terjadi di masyarakat Donggo, Kabupaten Bima dilatarbelakangi oleh adanya kesamaan tradisi leluhur. Selengkapnya baca, Kadri dkk., "Satu Leluhur Dua Agama," Laporan penelitian Lemlit IAIN Mataram tahun 2009. Demikian juga kerukunan yang terjalin antara warga Muslim dan Kristen yang ada di Klepu Ponorogo juga disatukan oleh kearifan Lokal setempat. Lihat, Marwan Sholahuddin, "Mengenal Kearifan Lokal di Klepu Ponorogo: Praktik Hubungan Sosial Lintas Agama dan Mekanisme Pencegahan Konflik" dalam Irwan Abdullah, dkk (ed.)., Agama dan Kearifan Lokal dalam Tantangan Global, (Yogyakarta: Pustaka Pelajar, 2008), h. 13-48. 
bahwa dalam masyarakat tradisional, meskipun sebuah komunitas telah memiliki mekanisme penyelesaian konflik sendiri, seperti tradisi Pelagandong di Sulawesi, tetapi tanpa inisiasi dari para pemimpin tersebut kearifan lokal ini tidak berfungsi secara maksimal.

\section{Ragam dan Pola Penanganan Konflik di Lombok}

Sebagaiman dipaparkan di bagian awal tulisan ini konflik berbau kekerasan di lombok kerap menghiasi media massa baik cetak maupun elektronik. Berdasarkan penyebab, konflik di Lombok bisa dikelompokan dalam beberapa kategori seperti konflik antar kampung, konflik keagamaan, konflik politik dan ekonomi, serta konflik budaya.

Tabel 1.

Sebaran Konflik di Lombok ${ }^{18}$

\begin{tabular}{|c|c|c|c|}
\hline Kategori & Bentuk & Lokasi & Penyebab \\
\hline \multirow[t]{3}{*}{$\begin{array}{l}\text { Konflik } \\
\text { Antar } \\
\text { kampung }\end{array}$} & $\begin{array}{l}\text { Bentrok antar } \\
\text { kampung Karang } \\
\text { Genteng dan } \\
\text { Patemon }\end{array}$ & Mataram & \multirow{2}{*}{$\begin{array}{l}\text { Tidak dapat diketahui secara } \\
\text { pasti penyebabnya karena } \\
\text { konflik terus berulang. Konflik } \\
\text { telah mulai sejak tahun } 1988 . \\
\text { Korban yang jatuh di salah } \\
\text { satu pihak menyebabkan den- } \\
\text { dam yang sulit diurai. Sebagi- } \\
\text { an pihak menyatakan pe- } \\
\text { rebutan lokasi makam akibat } \\
\text { pemekaran wilayah perkotaan } \\
\text { tahun } 1978 \text {. }\end{array}$} \\
\hline & $\begin{array}{l}\text { Karang Genteng } \\
\text { vs Pagutan } \\
\text { Presak }\end{array}$ & Mataram & \\
\hline & $\begin{array}{l}\text { Ketara vs } \\
\text { Penunjak } \\
\text { Ketara vs Batujai } \\
\text { Ketara vs } \\
\text { Sengkol } \\
\text { Ketara vs } \\
\text { Tenandon }\end{array}$ & Lombok Tengah & $\begin{array}{l}\text { Biasanya pemicunya (triger) } \\
\text { berupa hal-hal sepele seperti } \\
\text { perkelahian remaja yang ke- } \\
\text { mudian diikuti dengan per- } \\
\text { kelahian antar kampung. }\end{array}$ \\
\hline $\begin{array}{l}\text { Konflik } \\
\text { Keagamaan }\end{array}$ & $\begin{array}{l}\text { Ahmadiyah vs } \\
\text { warga } \\
\text { masyarakat }\end{array}$ & $\begin{array}{l}\text { Lombok Timur, } \\
\text { Lombok Barat }\end{array}$ & $\begin{array}{l}\text { Keyakinan Ahmadiyah yang } \\
\text { menganggap Mirza Ghulam } \\
\text { Ahmad sebagai nabi dianggap } \\
\text { menodai agama Islam }\end{array}$ \\
\hline
\end{tabular}

18 Diolah dari berbagai sumber. 


\begin{tabular}{|c|c|c|c|}
\hline & $\begin{array}{l}\text { Salafiyah vs } \\
\text { warga } \\
\text { masyarakat }\end{array}$ & $\begin{array}{l}\text { Lombok Barat, } \\
\text { Lombok Tengah } \\
\text { dan Lombok } \\
\text { Timur }\end{array}$ & $\begin{array}{l}\text { Kritik Salafi atas tradisi keber- } \\
\text { agamaan masyarakat Lombok } \\
\text { yang dianggap jauh dari ke- } \\
\text { murnian Islam. }\end{array}$ \\
\hline & $\begin{array}{l}\text { Warga Kel } \\
\text { Grunung Praya } \\
\text { vs Tarekat } \\
\text { Siratal } \\
\text { Mustaqim }\end{array}$ & Lombok Tengah & $\begin{array}{l}\text { Penyimpangan terhadap } \\
\text { aqidah islamiyah dan dugaan } \\
\text { isu mesum yang dilakukan } \\
\text { pimpinan tarekat }\end{array}$ \\
\hline & $\begin{array}{l}\text { NW Pancor vs } \\
\text { NW Anjani }\end{array}$ & Lombok Timur & $\begin{array}{l}\text { Dualisme kepengurusan pasca } \\
\text { Muktamar Praya }\end{array}$ \\
\hline & $\begin{array}{l}\text { Kasus "171" } \\
\text { (Kerusuhan 17- } \\
\text { 1-tahun 2000) }\end{array}$ & Mataram & $\begin{array}{l}\text { Respons terhadap konflik ke- } \\
\text { agamaan di Maluku dan } \\
\text { Ambon }\end{array}$ \\
\hline \multirow[t]{2}{*}{$\begin{array}{l}\text { Ekonomi } \\
\text { dan Politik }\end{array}$} & $\begin{array}{l}\text { Konflik } \\
\text { pembangunan } \\
\text { Bandara } \\
\text { Internasional } \\
\text { Lombok (BIL) }\end{array}$ & Lombok Tengah & $\begin{array}{l}\text { Pembebasan lahan milik } \\
\text { petani oleh pihak Angkasa } \\
\text { pura }\end{array}$ \\
\hline & $\begin{array}{l}\text { PNS dengan } \\
\text { Pemda Lombok } \\
\text { Timur }\end{array}$ & Lombok Timur & $\begin{array}{l}\text { Kebijakan pembayaran zakat } \\
\text { bagi PNS kepada Bazda Lotim } \\
\text { melalui perda no } 9 \text { tahun } \\
2002\end{array}$ \\
\hline
\end{tabular}

Berikut akan dipaparkan secara sekilas sebaran konflik yang terjadi di Lombok dalam satu dasawarsa terakhir.

Di awal tahun 2000, konflik bernuansa agama meletus di Lombok. Konflik ini bermula dari kegiatan tabligh akbar di lapangan umum kota Mataram yang digagas sejumlah ormas Islam Lombok yang dimaksudkan sebagai bentuk solidaritas umat Muslim NTB terhadap sesama Muslim di Maluku dan Ambon yang kala itu sedang konflik dengan Kristen. Para penceramah yang tidak hanya datang dari Tuan Guru di Lombok tetapi juga dari luar kota Mataram menghimbau agar umat Islam memberi simpati dan dukungan terhadap saudara-saudara Muslim yang sedang "dizalimi" di Maluku dan Ambon. Usai kegiatan tabligh akbar, jamaah pengajian yang telah terbakar emosinya kemudian bergerak menuju beberapa gereja dan melakukan penyerangan dan pembakaran. ${ }^{19}$ Aktivitas berikutnya diikuti dengan sweeping

19 Jacques Bertrand, Nationalism and Ethnic Conflict in Indonesia, (New York: Cambridge University Press, 2004), p. 132. 
beberapa rumah orang Cina dan melakukan perusakan. Sejumlah gereja terbakar dan banyak warga Tionghoa terpaksa harus eksodus dari Mataram.

Konflik organisasi keagamaan juga terjadi di Lombok yakni konflik di tubuh Nahdlatul Wathan (NW), sebuah organisasi keagamaan terbesar di Provinsi NTB. Konflik terjadi karena adanya perpecahan di tubuh NW yang kemudian menghasilkan dua kepengurusan di tubuh NW, yakni NW Anjani (para pengurus berpusat di desa Anjani) yang dipimpin oleh $\mathrm{Hj}$. Raehanun dan NW Pancor (berpusat di Pancor) yang dipimpin oleh Rauhun. Kedua tokoh ini adalah putri TGK Muhammad Zaenuddin Abdul Majid yang merupakan pendiri Nahdlatul Wathan. Konflik kedua kubu ini berlangsung cukup lama dan di tingkat grass root konflik ini sampai memakan korban jiwa. Namun yang menggembirakan, sekarang ini kedua kubu di bawah inisiasi Gubernur NTB, Muhamad Zainul Majdi (Tuan Guru Bajang), yang nota bene merupakan cucu dari Maulana Syaikh pendiri NW sedang mengupayakan iṣlāḥ (perdamaian).

Kasus konflik yang kerap berulang dan hingga kini belum memperoleh penyelesaian secara tuntas adalah kasus penyerangan Jemaat Ahmadiyah. Sebagaimana konflik yang terjadi di daerah lain seperti di Parung Bogor, konflik yang melibatkan warga dengan Ahmadiyah juga sering terjadi di pulau Lombok. Salah satu koran lokal, Bali Post edisi Minggu, 5 Februari 2006 mendokumentasikan sejumlah konflik yang yang menimbulkan kerugian di kalangan Ahmadiyah sebagaimana tampak dalam tabel berikut:

Tabel 2.

Kerusuhan Jemaat Ahmadiyah ${ }^{20}$

\begin{tabular}{|l|l|l|}
\hline \multicolumn{1}{|c|}{ Waktu } & \multicolumn{1}{c|}{ Tempat } & \multicolumn{1}{c|}{ Korban } \\
\hline 15 September 2002 & Pancor Lotim & 8 rumah dibakar, 28 dirusak \\
\hline Juni 2005 & Di Bogor, Jabar & Tempat ibadah dirusak \\
\hline 19 Oktober 2005 & Dusun Ketapang Lobar & Puluhan rumah dirusak \\
\hline 4 Februari 2006 & Dusun Ketapang Lobar & $\begin{array}{l}\text { 13 rumah dirusak dan } \\
\text { dibakar massa }\end{array}$ \\
\hline
\end{tabular}

${ }^{20}$ Bali Post edisi Minggu, 5 Februari 2006. 
Hingga kini warga Ahmadiyah yang menjadi korban masih mengungsi di wisma Transito Mataram. Selama tiga tahun lebih mereka menghuni wisma penampungan yang kurang layak huni mendorong mereka kembali ke rumah di Ketapang Lombok Barat. Akan tetapi sesampai di rumah mereka, massa kembali merusak rumah yang telah lama mereka tinggalkan. Peristiwa ini terjadi pada tanggal 26 November 2010. Hingga saat ini nasib warga Ahmadiyah masih belum jelas. Pemerintah Kabupaten Lombok Barat memberi solusi berupa "transmigrasi" bagi warga Ahmadiyah ke pulau tersendiri. Namun tawaran ini ditolak oleh sejumlah warga mengingat langkah ini hanya akan mengisolasi mereka.

Kekerasan tidak hanya menimpa mereka yang dianggap menyimpang (heterodoks), seperti Ahmadiyah, sebagian anggota masyarakat juga menyerang anggota kelompok Salafi. Kelompok keagaman yang menekankan pada kegiatan purifikasi agama ini telah beberapa kali mendapatkan resistensi dari masyarakat. Tercatat kekerasan terjadi beberapa kali di sejumlah tempat seperti di Gelogor Kecamatan Sekotong Tengah, di Dusun Beroro Desa Jembatan Kembar Kecamatan Lembar, desa Sesela kecamatan Gunung Sari dan di Dusun Mesanggok Desa Gapuk Kecamatan Gerung semuanya di wilayah Kabupaten Lombok Barat. ${ }^{21}$ Selain itu sebelumnya kekerasan juga terjadi terhadap pengikut aliran Wahabi di Kecamatan Masbagik Lombok Timur.

Dari serangkaian konflik yang ada, pola penanganan konflik biasanya dilajukan dengan penerjunan sejumlah aparat kepolisian. Selanjutnya pihak kepolisian, aparat Pemda dan sejumlah tokoh agama memanggil para pihak yang bertikai untuk melakukan dialog dan mencapai kesepakatan agar konflik dihentikan. Langkah peace keeping ini penting untuk menjaga agar kekerasan berhenti dan korban di kedua belah pihak tidak terus berlanjut. Proses penyeledikan dan penindakan terhadap mereka yang menjadi pelaku biasanya tidak diteruskan secara tuntas. Akibatnya bisa ditebak; proses penegakan hukum harus berhenti. Untuk sementara waktu pola semacam ini efektif, tetapi tidak menjamin adanya konflik di kemudian hari. Terbukti sejumlah konflik masih terus saja terjadi hingga kini.

${ }^{21}$ Faizah, "Dakwah Salafiyah di Lombok (Suatu Kajian Komunikasi antar Budaya)," Disertasi, (Jakarta: UIN Syarif Hidayatullah, 2010), h. 185. 


\section{E. Beberapa Kearifan Lokal Masyarkat Sasak}

Melihat tingginya frekuensi dan eskalasi konflik serta dampak sosial yang ditimbulkan muncul sejumlah pertanyaan. Pertama, mengapa konflik sedemikian mudah terjadi di daerah yang dulunya dikenal adem ayem ini. Kedua, mengapa pola penanganan konflik yang dilakukan para elit baik agama, adat maupun pemerintah terkesan hanya menyelesaikan konflik atau menghentikan konflik. Tindakan penghentikan konflik belum diikuti dengan langkah-langkah upaya bina damai (peace building) yang berkelanjutan. Beberapa peristiwa konflik seperti kasus Ahmadiyah, Salafi dan sejumlah konflik antar kampung bisa berlangsung secara berulang-ulang padahal penyebabnya hampir sama. Jika diamati secara seksama pola penyelesaian konflik masih berlangsung secara sepihak. Acap terjadi dalam proses penyelsaian konflik para elit bertindak atas nama dan untuk kepentingan mayoritas. Korban konflik malah kerap dijadikan korban (victimizing victims).

Dalam komunitas Sasak, sejumlah nilai lokal sejatinya dapat dikembangkan sebagai upaya mengelola konflik dan membangun harmoni. Nilai-nilai kearifan lokal (local wisdom) bisa dilacak dari naskah kuno Kotaragama, sesengak (peribahasa), perteke, atau lelakaq (pantun). Sebuah tulisan berjudul "Nilai-nilai Kearifan Lokal yang Berlaku pada Masyarakat Sasak sebagai Pola Budaya" yang ditulis oleh H.L. Syapruddin mengelaborasi secara singkat beberapa local wisdom ini.

Tabel 3.

Kearifan Lokal Pada Masyarakat Sasak - Lombok NTB ${ }^{22}$

\begin{tabular}{|l|l|l|l|}
\hline \multicolumn{1}{|c|}{ Prinsip } & \multicolumn{1}{c|}{ Sumber } & \multicolumn{1}{c|}{ Ungkapan } & \multicolumn{1}{c|}{ Makna } \\
\hline $\begin{array}{l}\text { Kejujuran dan } \\
\text { kesetiaan } \\
\text { memegang janji }\end{array}$ & $\begin{array}{l}\text { Naskah Kuno } \\
\text { KOTARAGAMA }\end{array}$ & $\begin{array}{l}\text { Danta, Danti, } \\
\text { Kusuma Warsa. }\end{array}$ & $\begin{array}{l}\text { Kata dan janji wajib } \\
\text { dipegang dan diper- } \\
\text { tahankan dengan } \\
\text { kukuh. }\end{array}$ \\
\cline { 2 - 4 } & SESENGAK & $\begin{array}{l}\text { Sampi betali isik } \\
\text { pepit, manuse betali } \\
\text { isik raos. }\end{array}$ & $\begin{array}{l}\text { Manusia diikat } \\
\text { dengan kata - } \\
\text { katanya. }\end{array}$ \\
\hline
\end{tabular}

22 Dikutip dari H.L. Syapruddin, "Nilai-nilai Kearifan Lokal yang Berlaku pada Masyarakat Sasak sebagai Pola Budaya," makalah disampaikan pada Seminar Budaya di Taman Budaya Mataram. 


\begin{tabular}{|c|c|c|c|}
\hline \multirow[t]{4}{*}{$\begin{array}{l}\text { Menegakkan / } \\
\text { mensucikan } \\
\text { ajaran agama }\end{array}$} & \multirow[t]{4}{*}{ PERTEKE } & $\begin{array}{l}\text { Agama betakaq } \\
\text { adat. }\end{array}$ & $\begin{array}{l}\text { Adat menegakkan } \\
\text { dan mensucikan } \\
\text { agama. }\end{array}$ \\
\hline & & $\begin{array}{l}\text { Ndaq ta ngaken } \\
\text { baraq api. }\end{array}$ & $\begin{array}{l}\text { Larangan memakan } \\
\text { riba. }\end{array}$ \\
\hline & & $\begin{array}{l}\text { Pacu-pacu punik } \\
\text { akherat. }\end{array}$ & $\begin{array}{l}\text { Bersungguh- sungguh } \\
\text { berbuat kebajikan }\end{array}$ \\
\hline & & $\begin{array}{l}\text { Rurung bender } \\
\text { turna gantar. }\end{array}$ & $\begin{array}{l}\text { Sejahtera dan } \\
\text { tenteram jika } \\
\text { menegakkan ajaran } \\
\text { agama. }\end{array}$ \\
\hline $\begin{array}{l}\text { Persamaan dan } \\
\text { kebersamaan } \\
\text { hak }\end{array}$ & SESENGAK & $\begin{array}{l}\text { Pusaka tolang daeng } \\
\text { papuk balok. } \\
\text { Dowe tengaq, Dowe } \\
\text { sopoq. } \\
\text { Nemu syarat kepeng. } \\
\text { Dowen neneq. } \\
\text { Dowen pelungguh saq } \\
\text { leq tiang. }\end{array}$ & \\
\hline Kemanusiaan & $L E L A K A Q$ & $\begin{array}{l}\text { Anak kaoq } \\
\text { mondong jagung, } \\
\text { sai tao jari agung. } \\
\text { Ulah mandi isiq } \\
\text { bisana. }\end{array}$ & \\
\hline $\begin{array}{l}\text { Pemeliharaan } \\
\text { lingkungan }\end{array}$ & $\begin{array}{l}\text { UNGKAPAN } \\
\text { LOKAL }\end{array}$ & $\begin{array}{l}\text { Kurenan, gubuk, } \\
\text { lambah, } \\
\text { penyengker, } \\
\text { nambarayang, cero, } \\
\text { kuninga, penyaweq, } \\
\text { uriga, maliq. }\end{array}$ & \\
\hline $\begin{array}{l}\text { Perekonomi dan } \\
\text { etos kerja }\end{array}$ & $\begin{array}{l}\text { UNGKAPAN } \\
\text { LOKAL DAN } \\
\text { SESENGAK }\end{array}$ & $\begin{array}{l}\text { Keduk lindung bani } \\
\text { raok; Mesang ime } \\
\text { naen ta bawaq lanjaq } \\
\text { batur Nyuit isiq jaum; } \\
\text { Tiwas karang jari } \\
\text { apuh; } \\
\text { Manah tan keneng } \\
\text { obah; Kendeq } \\
\text { nenggala leq atas } \\
\text { bonggkor batur; } \\
\text { Soroq dampuk bosang } \\
\text { boros }\end{array}$ & $\begin{array}{l}\text { perlu pengorbanan } \\
\text { demi cita-cita. }\end{array}$ \\
\hline
\end{tabular}




\begin{tabular}{|l|l|l|l|}
\hline $\begin{array}{l}\text { Penyelesaian } \\
\text { konflik }\end{array}$ & SESENGAK & $\begin{array}{l}\text { Empaq bau, aiq } \\
\text { meneng, tunjung } \\
\text { tilah; }\end{array}$ & $\begin{array}{l}\text { Kepuasan tidak ada } \\
\text { merasa ditekan, } \\
\text { semua merasa me- }\end{array}$ \\
& & Adiq ta tao jauq aiq; \\
Sifat anaq empaq, & nang. \\
tao pesopoq diriq; & Harus mampu \\
menjadi pen- \\
dikut tanggkong leq \\
dingin/penyejuk. \\
\end{tabular}

Kedamaian dan harmoni sebetulnya merupakan kultur dominan masyarakat Sasak. Sejumlah idiom yang dikenal di lingkungan masyarakat Sasak sangat dekat dengan orientasi kedamaian. Konsep ajinin yang secara harfiah berarti saling menghormati, reme, rapah, regen yang berarti suka memberi, memilih situasi aman damai dan mendukung toleransi menambah khazanah kearifan lokal masyarakat Lombok dalam menajalani relasi sosial. ${ }^{23}$

Selain terdapat sejumlah petuah lama yang menjadi nilai-nilai luhur yang mengatur interaksi sosial, di Pulau Lombok terdapat pula banyak tradisi yang jika ditelusuri dapat menjadi bagian dari upaya bina damai (peace building). Tradisi-tradisi tersebut hingga kini masih dipraktikan di komunitas Sasak terutama di daerah pedesaan. Hampir keseluruhan tradisi ini mengarah pada upaya menjaga harmoni sosial. Seperti budaya rowah, yang berarti pesta. Dalam banyak kesempatan seperti upacara kelahiran, pernikahan hingga kematian serta aktivitas perayaan hari besar keagamaan seperti maulid nabi, Isrā' wa 'l-mi'rāj, dan lain-lain sebuah keluarga biasanya memasak makanan dan mengundang tetangga, teman, sanak sadara untuk makan bersama. Mereka secara kekeluargaan melakukannya dengan cara duduk bersila melingkar dan bersama-sama menyantap makanan yang dihidangkan. Aktivitas ini biasanya disebut begibung.

Dalam begibung, semua orang duduk sejajar tanpa dibedakan status sosialnya. Mereka membaur menjadi satu dan dalam suasana penuh kekeluargaan. Meskipun sejumlah orang tokoh seperti tuan guru dan kiai biasanya memperoleh hidangan lebih awal ketimbang warga yang lain tetapi

23 http://www.budpar.go.id/filedata/5199_1443-5.keragamanbudaya1oke.pdf, diakses pada tangal 5 Desember 2010. 
secara keseluruhan posisi mereka dalam proses begibung adalah sama. Menyantap nakanan tanpa menggunakan sendok (muluk: Jawa), semua orang merasakan menu masakan yang sama sambil bercengkerama secara lepas. Tradisi ini jelas menggambarkan adanya kerukunan dan harmoni diantara warga. Semangat menjalin silaturahim sangat kental dalam kegiatan ini. Praktik ini sama dengan tradisi slametan dalam komunitas Jawa. Slametan dalam tradisi masayarakat Jawa sebagaimana ditemukan Geertz di daerah penelitiannya, Mojokuto merupakan tradisi bagi masyarakat Jawa yang selalu diulang dan berlangsung untuk banyak siklus. Seperti siklus kelahiran, tradisi slametan meliputi: telonan, tingkeban, babaran, sepasaran, selapanan, pitonpiton dan setahunan.$^{24}$ Demikian halnya dalam tradisi Sasak aktivitas rowah yang didalamnya terdapat begibung juga berlangsung dalam banyak siklus. Seperti dalam kegiatan mendoakan keluarga yang meninggal meliputi sejumlah siklus seperti, nelung (tiga hari), mitu' (tujuh hari), nyiwa' (sembilan hari), metang dasa (empat puluh hari), nyatus (seratus hari), nanun (kelima ratus hari), nyangga (kesembilan ratus hari), nyiu (keseribu hari). Namun pada saat ini aktivitas selamatan biasanya hanya sampai nyatus (seratus hari)..$^{25}$

Jika keluarga mempunyai hajat (begawe) maka warga dengan sukarela akan membantunya. Mulai dari menyumbang kebutuhan bahan mentah yang diperlukan, seorang laki-laki biasanya membawa kelapa sekaligus memecahnya di tempat keluarga yang punya hajat dengan parang yang dibawa dari rumah hingga menyiapkan semua perlengkapan dan sarana yang diperlukan. Sedangkan para wanita dengan sukarela membantu memasak makanan dan menghidangkannya. Semua ini dilakukan warga terhadap semua orang yang mempunyai hajat, meskipun orang tersebut merupakan pendatang baru.

Di luar falsafah hidup yang dapat digali dari kearifan lokal dan beberapa living tradition di atas, pada beberapa desa di Lombok terdapat pula sejumlah aturan yang disepakati bersama oleh anggota masyarakat dan menjadi semacam hukum tak terlulis. Aturan yang disepakati bersama ini dinamakan awig-awig. Awig-awig ada yang tertulis ada yang tak tertulis. Dalam praktik-

\footnotetext{
24 Marwan Sholahuddin, "Mengenal Kearifan Lokal di Klepu Ponorogo: Praktik Hubungan Sosial Lintas Agama dan Mekanisme Pencegahan Konflik" dalam Irwan Abdullah, dkk. (ed.), Agama dan Kearifan Lokal dalam Tantangan Global, (Yogyakarta: Pustaka Pelajar, 2008), h. 13-48.

${ }^{25}$ Faizah, "Dakwah Salafiyah di Lombok....," h. 146.
} 
nya awig-awig ini dapat lebih efektif dibanding hukum formal yang dikonstruk negara. Rumusan awig-awig yang bersumber dari masyarakat dan dirumuskan secara partisipatif, mendorong masyarkat dengan sukarela mentaati dan menjaganya. Jadi ketaatan yang muncul lebih karena kesadaran bukan paksaan.

\section{F. Kesimpulan}

Mencermati konflik dan potensi konflik yang ada di banyak daerah termasuk di Lombok ditambah pola penanganan yang belum mengarah pada transformasi konflik menjadi energi positif masyarakat, maka pilihan terhadap kearifan lokal masyarakat bisa menjadi alternatif. Pelibatan kearifan lokal dalam resolusi konflik dan bina damai, jelas bukan merupakan satusatunya cara. Beberapa tahapan resolusi konflik mesti juga dilalui sesuai dengan tahapan dan eskalasi konflik. Penekananya adalah bahwa pola-pola penanganan konflik yang masih sebatas penghentian konflik perlu ditingkatkan ke arah kerja bina damai (peace building) dengan melibatkan kearifan lokal yang telah terbukti mampu menjaga harmoni sosial masyarakat. Mengingat aturan-aturan dan norma-norma ini telah lama terinternalisasi di masyarakat sehingga penghargaan dan penerimaan sebuah keputusan akan bertahan lama. Karena sejatinya apa yang muncul dari hasil kesepakatan tersebut merupakan kehendak bersama masyarakat.

Hal penting yang diperlukan adalah kesediaan dari para elit baik elit agama (Tuan Guru, kiai), elit pemerintah dan elit adat untuk duduk bersama mengembangkan pola bina damai berbasis kearifan lokal. Kesediaan para elit terhadap prakarsa bina damai ini penting mengingat meskipun sebuah daerah telah memiliki serangkaian nilai-nilai lokal dan mekanisme resolusi konflik, tetapi semuanya akan sulit berjalan tanpa keterlibatan elit secara aktif. Untuk itu diperlukan penguatan di tingkat elit agar nilai-nilai kearifan lokal dapat dikembangkan menjadi bagian dari upaya resolusi konflik dan prakarsa perdamaian di masa depan. Potensi ini sangat mungkin dikembangkan tanpa harus bertabrakan dengan kaidah-kaidah Islam sebagai agama mayoritas masyarakat Lombok. Karena dalam Islam sendiri konsep semisal 'urf atau al-'addah al-ma'rifah merupakan konsep yang selama ini menjadi bagian dari sumber hukum.

Pilihan penguatan dapat dilakukan dengan banyak cara sesuai kultur lokal. Mulai dari kegiatan sangkep (pertemuan, seminar), gundem ( musya- 
warah), hingga pelatihan (training), yang difasilitasi oleh pemerintah atau lembaga swadaya masyarakat yang peduli akan hal ini. Selebihnya dalam bidang pendidikan baik formal (sekolah, madrasah) maupun non-formal (pesantren), pengembangan kurikulum muatan lokal hendaknya memperhatikan kearifan lokal ini. Sebagaimana watak dari kearifan lokal sendiri yang merupakan sendimentasi dari proses dinamika masyarakat dalam kurun waktu yang lama. Maka eksistensinya akan sangat tergantung dari kesediaan para aktor lokal dalam merawat dan mentransmisikan nilai-nilai tersebut dari generasi ke generasi.[w] 


\section{BIBLIOGRAFI}

Ashutosh Varshney et.al., "Pattern of Collective Violence in Indonesia (19902003)," UNSFIR (United Nation Support Facility for Indonesian Recovery), Jakarta: Report UNSFIR, 2004.

Benedict Anderson, Imagined Communities: Reflections on the Origin and Spread of Nationalism, London and New York: Verso, 1991

CA. Coppel (eds.), Violent Conflicts in Indonesia: Analysis, Representation, Resolution, London: Routledge, 2005.

Craig Calhoun, "Nationalism and Civil Society: Democracy, Diversity and Self Determination," in Craig Calhoun (eds.), Social Theory and the Politics of Identity, Oxford: Blackwell Publisher, 1998.

Faizah, "Dakwah Salafiyah di Lombok (Suatu Kajian Komunikasi antar Budaya)," Disertasi Jakarta: UIN Syarif Hidayatullah, 2010.

Gerry van Klinken, Communal Violence and Democratization in Indonesia: Small Town Wars, London: Routledge, 2007.

H.L. Syapruddin, "Nilai-nilai Kearifan Lokal yang Berlaku pada Masyarakat Sasak sebagai Pola Budaya," makalah disampaikan pada seminar budaya di Taman Budaya Mataram.

Irwan Abdullah, dkk., (ed.), Agama dan Kearifan Lokal dalam Tantangan Global, Yogyakarta: Pustaka Pelajar, 2008.

Jacques Bertrand, Nationalism and Ethnic Conflict in Indonesia, New York: Cambridge University Press, 2004.

Jajat Burhanuddin dan Arif Subhan, (ed.), Sistem Siaga Dini terhadap Kerusuhan Sosial, Jakarta: Balitbang Agama Depag RI dan PPIM, 2000.

John Ryan Bartholomew, Alif Lam Mim Kearaifan Masyarakat Sasak, terj. Imron Rasyidi, Yogyakarta: Tiara Wacana, 2001.

J. Rothman, From Confrontation to Cooperation: Resolving Ethnic and Regional Conflict, Newbury Park, CA: Sage, 1992.

Lewis Coser, The Function of Social Conflict, New York: Free Press, 1965.

Kadri, dkk., "Satu Leluhur Dua Agama," Laporan Penelitian, Lemlit IAIN Mataram Tahun 2009. 
Khamami Zada, dkk., Prakarsa Perdamaian: Pengalaman dari Berbagai Konflik Sosial, Jakarta: Penerbit Lakpesdam NU, 2008.

Marwan Sholahuddin, "Mengenal Kearifan Lokal di Klepu Ponorogo: Praktik Hubungan Sosial Lintas Agama dan Mekanisme Pencegahan Konflik" dalam Irwan Abdullah, dkk (Ed)., Agama dan Kearifan Lokal dalam Tantangan Global, Yogyakarta: Pustaka Pelajar, 2008.

Muhsin Jamil, M., (ed). Mengelola Konflik Membangun Damai: Teori, Strategi dan Implementasi Resolusi Konflik, Semarang: Walisongo Mediation Centre, 2007.

Nurma Ali Ridwan, “ Landasan Keilmuan Kearifan Lokal” Ibda’, Vol. 5, No. 1, JanJun. 2007.

Nicola Colbran, "Realities and Challenges in Realising Freedom of Religion or Belief in Indonesia" The International Journal of Human Rights, Vol. 14, No. 5, September 2010.

Ralf Dahrendorf, Class and Class Conflict in Industrial Society, Stanford: Stanford University Press, 1959.

Simon Fisher, etal, Mengelola Konflik Ketrampilan dan Strategi Untuk Bertindak, terj. S.N. Karikasari, dkk, Jakarta: The British Council Responding to Conflict, t.th.

Syafuan Rozi dkk, Kekerasan Komunal: Anantomi dan Resolusi Konflik di Indonesia, Jakarta: Pustaka Pelajar, 2006.

\section{Internet dan Surat Kabar:}

Bali Post, edisi Minggu, 5 Februari 2006

http://www.budpar.go.id/filedata/5199_1443-5.keragamanbudaya1oke.pdf diakses pada tangal 5 Desember 2010. 